\title{
Mono Azo Dyes Compounds as Corrosion Inhibitors for Dissolution of Aluminium in Sodium Hydroxide Solutions
}

\author{
Salih S. Al-Juaid * \\ Chem. Dept., Faculty of Science, King Abdulaziz University, P.O. Box 80203, Jeddah 21589, \\ Saudi Arabia
}

Received 5 November 2006; accepted 19 July 2007

\begin{abstract}
The effect of some mono azo dyes compounds on the dissolution of aluminium in 0.01 $\mathrm{M} \mathrm{NaOH}$ solutions was studied using weight loss and galvanostatic polarization techniques. The percentage inhibition efficiency was found to increase with increasing concentration of inhibitor and with decreasing temperature. The inhibition mechanism was discussed on the basis of the formation of complex compound adsorbed on the metal surface. The adsorption process follows Frumkin isotherm. The effect of temperature on the rate of corrosion in the absence and presence of these compounds was also studied. Some activated thermodynamic parameters were computed.
\end{abstract}

Keywords: mono azo dyes, aluminium, inhibitors.

\section{Introduction}

Aluminium (Al) and its alloys are widely used in technology because of their low density, pleasing appearance, and corrosion resistance. For these reasons, the corrosion inhibition of $\mathrm{Al}$ in aqueous solution, has attracted the attention of many investigators [1-7]. Inhibition of metal corrosion by organic compounds is a result of adsorption of organic molecules or ions at the metal surface forming a protective layer. This layer reduces or prevents the corrosion of the metal. The extent of adsorption depends on the nature of the metal, the metal surface condition, the mode of adsorption, the chemical structure of the inhibitor, and the type of corrosive media [8].

The aim of the present work is to study the inhibitive action of some mono azo dyes based on 1,5-dihydroxynanphthalene toward the corrosion inhibition of aluminium in $0.01 \mathrm{M} \mathrm{NaOH}$ solution using weight loss and galvanostatic polarization techniques. The effect of temperature on the dissolution of

\footnotetext{
*Corresponding author. E-mail address: ssaljuaid@hotmail.com
} 
aluminium in free and inhibited alkali solution was also investigated, and some thermodynamic parameters for activation process were computed.

\section{Experimental methods}

All metal with purity $99.99 \%$ was used in the present study. Al sheets with dimension 1 x 4 x $0.1 \mathrm{~cm}$ were used for weight loss measurements. For galvanostatic polarization, a cylindrical rod embedded in araldite with an exposed bottom surface area of $0.82 \mathrm{~cm}^{2}$ was used. The electrode was polished with different grades emery paper, degreased with acetone and rinsed in distilled water.

Weight loss measurements were carried out as described elsewhere [9]. Galvanostatic polarization measurements were carried out using EG and G model 173 potentiostat / galvanostat. The electrode potential was measured against a saturated calomel electrode (SCE). A platinum foil was used as an auxiliary electrode.

The percentage inhibition efficiency (IE) of the azo dyes compounds was calculated from weight loss measurements using the following equation:

$$
\text { I.E. }=\left[1-\frac{\mathrm{W}_{\mathrm{add}}}{\mathrm{W}_{\text {free }}}\right] 100
$$

where, $\mathrm{W}_{\text {add }}$ and $\mathrm{W}_{\text {free }}$ are the weight loss of the metal in the presence and absence of the inhibitor.

The values of I.E. of the azo dyes compounds were calculated from galvanostatic polarization technique using the following equation:

$$
\text { I.E. }=\left[1-\frac{I_{\text {corr., add }}}{I_{\text {corr.,free }}}\right] 100
$$

Chemical structure of mono azo dyes compounds:<smiles>[X]c1ccccc1/N=N/c1ccc(O)c2cccc(O)c12</smiles>

where $\mathrm{X}=\mathrm{Cl}, \mathrm{H}, \mathrm{OCH}_{3}$ 


\section{Results and discussion}

\section{Weight loss measurements}

Fig. 1 represents the relation between time and weight loss of $\mathrm{Al}$ sheet in $0.01 \mathrm{M}$ $\mathrm{NaOH}$ solution in the absence and presence of different concentrations of compound III as an example. Similar curves were also obtained for other two compounds (not shown). It is obvious that the weight loss of Al in presence of the inhibitor varies linearly with time, and is much lower than that obtained in the blank solution. The linearity obtained indicates the absence of insoluble surface film during corrosion and that the inhibitors were first adsorbed onto the surface and thereafter impede the corrosion process [10].

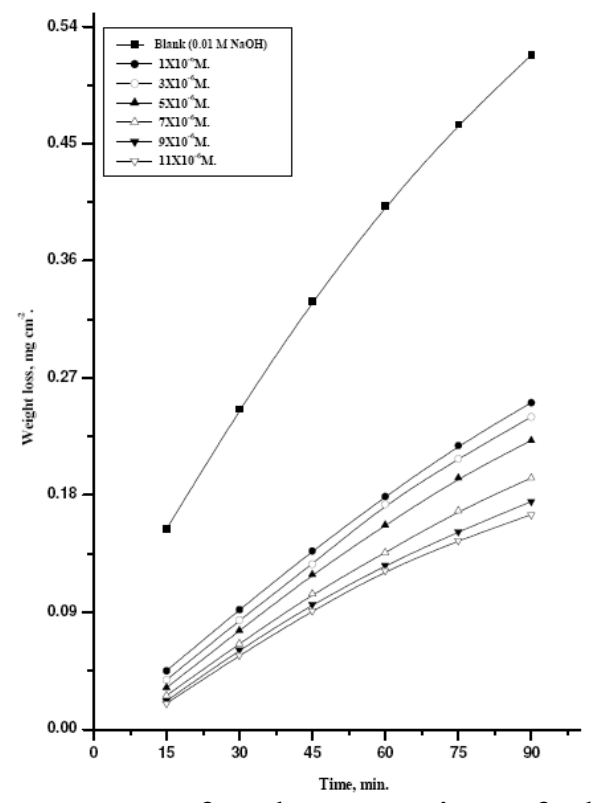

Figure 1. Weight loss-time curves for the corrosion of aluminium in presence and absence of different concentrations of compound (III) at $30^{\circ} \mathrm{C}$.

The calculated values of inhibition efficiency (IE) from weight loss measurements are listed in Table 1. It is obvious that the values of IE increase with the inhibitor concentration, whereas decrease in the following order: Compound III > Compound II > Compound I. This behavior will be discussed later.

\section{Adsorption isotherm}

The degree of surface coverage $(\theta)$ of Al electrode by adsorption of mono azo dyes compounds was calculated using the following equation:

$$
\theta=1-\frac{\mathrm{W}_{\text {add }}}{\mathrm{W}_{\text {free }}}
$$

where $\mathrm{W}_{\text {add }}$ and $\mathrm{W}_{\text {free }}$ were defined before. 
Table 1: Effect of mono azo dyes compounds on the inhibition efficiency (\% I.E.) and surface coverage $(\theta)$ obtained from weight loss measurements for dissolution of $\mathrm{Al}$ in $0.01 \mathrm{M} \mathrm{NaOH}$.

\begin{tabular}{|c|c|c|}
\hline \multirow{2}{*}{$0.01 \mathrm{MNaOH}+$ Compound I } & \% I.E. & $\theta$ \\
\hline & & \\
\hline $1 \times 10^{-6} \mathrm{M}$ compound I & 30.15 & 0.30 \\
\hline $3 \times 10^{-6} \mathrm{M}$ compound I & 31.28 & 0.31 \\
\hline $5 \times 10^{-6} \mathrm{M}$ compound I & 34.04 & 0.34 \\
\hline $7 \times 10^{-6} \mathrm{M}$ compound I & 37.22 & 0.37 \\
\hline $9 \times 10^{-6} \mathrm{M}$ compound I & 40.15 & 0.40 \\
\hline $11 \times 10^{-6} \mathrm{M}$ compound I & 42.76 & 0.43 \\
\hline $0.01 \mathrm{MNaOH}+$ Compound II & & \\
\hline $1 \times 10^{-6} \mathrm{M}$ compound II & 38.25 & 0.38 \\
\hline $3 \times 10^{-6} \mathrm{M}$ compound II & 40.76 & 0.41 \\
\hline $5 \times 10^{-6} \mathrm{M}$ compound II & 43.12 & 0.43 \\
\hline $7 \times 10^{-6} \mathrm{M}$ compound II & 47.22 & 0.47 \\
\hline $9 \times 10^{-6} \mathrm{M}$ compound II & 50.34 & 0.50 \\
\hline $11 \times 10^{-6} \mathrm{M}$ compound II & 53.18 & 0.53 \\
\hline $0.01 \mathrm{M} \mathrm{NaOH}+$ Compound III & & \\
\hline $1 \times 10^{-6} \mathrm{M}$ compound III & 54.22 & 0.54 \\
\hline $3 \times 10^{-6} \mathrm{M}$ compound III & 56.12 & 0.56 \\
\hline $5 \times 10^{-6} \mathrm{M}$ compound III & 59.13 & 0.59 \\
\hline $7 \times 10^{-6} \mathrm{M}$ compound III & 64.22 & 0.64 \\
\hline $9 \times 10^{-6} \mathrm{M}$ compound III & 68.26 & 0.68 \\
\hline $11 \times 10^{-6} \mathrm{M}$ compound III & 70.68 & 0.71 \\
\hline
\end{tabular}

The values of $\theta$ for different concentrations of the studied compounds (I-III) at $30{ }^{\circ} \mathrm{C}$ have been used to explain the best isotherm to determine the adsorption process. The adsorption of the azo dyes compounds, on the surface of aluminium electrode is regarded as a substitutional adsorption process between organic compounds in the aqueous phase $\left(\mathrm{Org}_{\mathrm{aq}}\right)$ and the water molecules adsorbed on the aluminium surface $\left(\mathrm{H}_{2} \mathrm{O}\right)$ ads $[11]$ :

$$
\mathrm{Org}_{(\mathrm{sol})}+\mathrm{X}\left(\mathrm{H}_{2} \mathrm{O}\right)_{\mathrm{ads}} \rightleftharpoons \mathrm{Org}_{(\mathrm{ads})}+\mathrm{XH}_{2} \mathrm{O} \text { sol }
$$

where $\mathrm{X}$ is the size ratio, that is the number of water molecules replaced by one organic molecule. Attempts were made to fit $\theta$ values to various isotherms, including Langmuir, Freundlich, Temkin and Frumkin isotherms. By far the results were best fitted by Frumkin adsorption isotherm according to the following equation [12]:

$$
\mathrm{KC}=\theta / 1-\theta \exp (-2 \mathrm{a} \theta)
$$

where $\mathrm{K}$ is the equilibrium constant of the adsorption reaction, $\mathrm{C}$ is the inhibitor concentration in the bulk of the solution and $\mathrm{a}$ is a molecular interaction parameter depending upon molecular interactions in the adsorption layer and the degree of heterogeneity of the surface. 
Plotting $\theta$ against $\log \mathrm{C}$ (Frumkin adsorption plots) for adsorption of the mono azo dyes compounds on the surface of aluminium in $0.01 \mathrm{M} \mathrm{NaOH}$ solution at 30 ${ }^{\circ} \mathrm{C}$ are shown in Fig. 2. The data gave S-shape curves indicating that Frumkin adsorption isotherm is valid for adsorption of these compounds on the surface of aluminium.

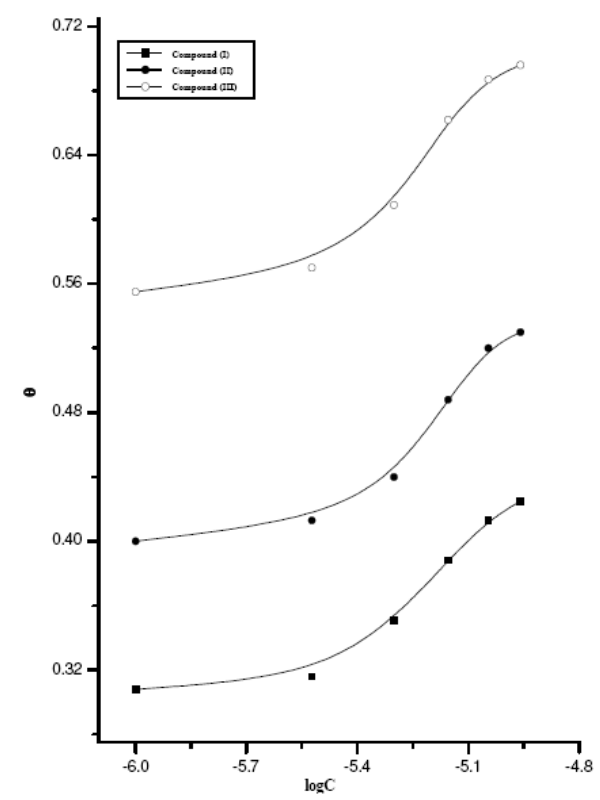

Figure 2. Curve fitting of corrosion data for aluminium in $0.01 \mathrm{M} \mathrm{NaOH}$ in the presence of different concentrations of the mono azo dyes compounds to Frumkin isotherms mono azo.

\section{Effect of temperature}

The effect of rising temperature on the corrosion rate of $\mathrm{Al}$ in $0.01 \mathrm{M} \mathrm{NaOH}$ solution in absence and presence of $5 \times 10^{-6} \mathrm{M}$ of the selected azo dyes compounds was studied by weight loss measurements over a temperature range from $30-50{ }^{\circ} \mathrm{C}$.

Fig. 3 shows the weight loss-time curves of $\mathrm{Al}$ electrode in $0.01 \mathrm{M} \mathrm{NaOH}$ containing $5 \times 10^{-6} \mathrm{M}$ of the compound III at different temperatures. Similar curves were obtained for other two compounds I and II (not shown). It is clear that the rate of corrosion increases as the temperature increases. This indicates that the rising of temperature decreases the inhibition efficiency and the best inhibition efficiency is obtained at $30^{\circ} \mathrm{C}$.

The activation energy $\left(\mathrm{E}_{\mathrm{a}}\right)$ of the corrosion process was calculated using Arrhenius equation [13]:

and logarithmic form:

$$
\mathrm{R}_{\text {corr. }}=\mathrm{A} \mathrm{e}^{-\mathrm{Ea} * / \mathrm{RT}}
$$

$$
\log \mathrm{R}_{\text {corr. }}=\log \mathrm{A}-\mathrm{Ea}^{*} / 2.303 \mathrm{RT}
$$

where $\mathrm{R}_{\text {corr }}$ is the corrosion rate, $\mathrm{A}$ is Arrhenius constant, $\mathrm{R}$ is the gas constant and $\mathrm{T}$ is the absolute temperature. 


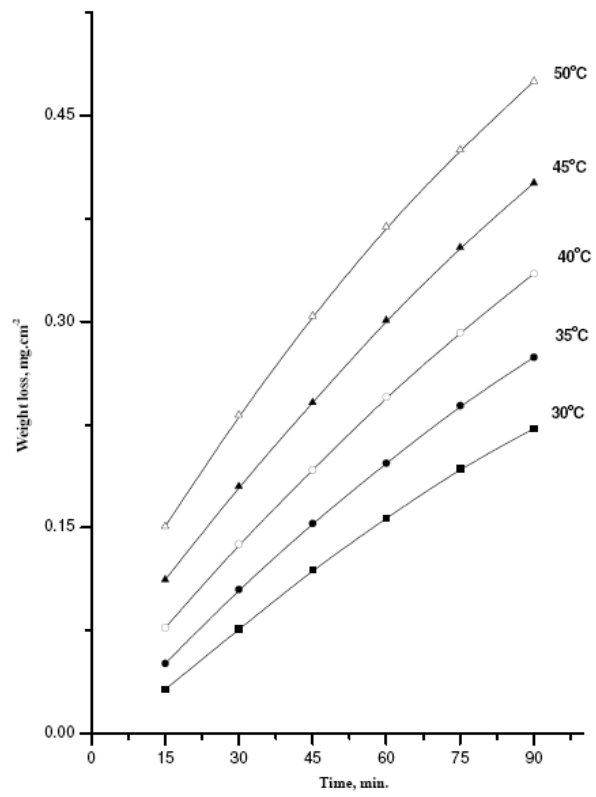

Figure 3. Weight loss-time curves for the corrosion of aluminium in $0.01 \mathrm{M} \mathrm{NaOH}$ in presence of $5 \times 10^{-6} \mathrm{M}$ of compound (III) at different temperatures.

Fig. 4 shows Arrhenius plot $\left(\log \mathrm{R}_{\text {corr. }}\right.$ Vs. 1/T) for uninhibited Al in $0.01 \mathrm{M}$ $\mathrm{NaOH}$ and in presence of the studied azo dyes compounds. The values of $\mathrm{E}_{\mathrm{a}}$ can be obtained from the slope of the straight lines and are given in Table (2). From ther inspection of Table (2), it is clear that the values of $\mathrm{Ea}^{*}$ increase in the presence of the inhibitors. This was attributed to an appreciable decrease in the adsorption process of the inhibitor on the metal surface with increase of temperature and corresponding increase in the reaction rate because of the greater area of the metal that is exposed to $\mathrm{NaOH}$ solution.

An alternative formulation of the Arrhenius equation is the transition state equation [15]:

$$
\mathrm{R}_{\text {corr. }}=\mathrm{RT} / \mathrm{Nh} \exp ^{\left(\Delta \mathrm{S}^{*} / \mathrm{R}\right)} \exp ^{\left(-\Delta \mathrm{H}^{*} / \mathrm{RT}\right)}
$$

where $\mathrm{h}$ is Planck's constant, $\mathrm{N}$ is Avogadro's number, $\Delta \mathrm{S}^{*}$ is the entropy of activation and $\Delta \mathrm{H}^{*}$ is the enthalpy of activation.

Table 2. Activation parameters of the dissolution of aluminium in $0.01 \mathrm{M} \mathrm{NaOH}$ in the absence and presence of $5 \times 10^{-6} \mathrm{M}$ of the mono azo dyes compounds.

\begin{tabular}{|c|c|c|c|}
\hline \multirow[t]{2}{*}{ Inhibitor } & \multicolumn{3}{|c|}{ Activation parameters } \\
\hline & $\mathrm{E}_{\mathrm{a}} \mathrm{KJ} \mathrm{mol}^{-1}$ & $\Delta \mathbf{H}^{*}, \mathrm{KJ} \mathrm{mol}^{-1}$ & $-\Delta S, J \mathrm{~mol}^{-1} \mathbf{k}^{-1}$ \\
\hline Free $\mathrm{NaOH}$ & 23.68 & 21.08 & 187.10 \\
\hline Compound I & 29.52 & 26.91 & 192.55 \\
\hline Compound II & 32.66 & 30.06 & 204.15 \\
\hline Compound III & 34.77 & 32.16 & 210.74 \\
\hline
\end{tabular}




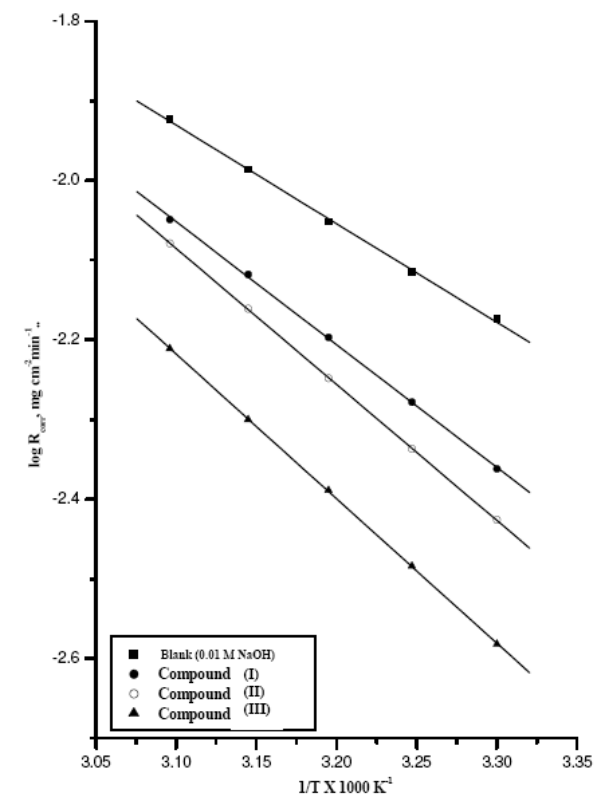

Figure 4. Relation between $\log \mathrm{R}_{\text {corr }}$ and the reciprocal of the absolute temperature of aluminium electrode in $0.01 \mathrm{M} \mathrm{NaOH}$ and in the presence of $5 \times 10^{-6} \mathrm{M}$ of the mono azo dyes compounds.

Fig. 5 shows a plot of $\log (\mathrm{K} / \mathrm{T})$ against $(1 / \mathrm{T})$. Straight lines are obtained with a slope of $\left(-\Delta H^{*} / 2.303 R\right)$ and an intercept of $\left(\log R / N h+\Delta S^{*} / 2.303 R\right)$ from which the values of $\Delta \mathrm{H}^{*}$ and $\Delta \mathrm{S}^{*}$ are calculated and listed in Table 2 .

From inspection of Table (2) it is clear that the positive values of $\Delta \mathrm{H}^{*}$ reflect that the process of adsorption of the inhibitors on the aluminium surface is an endothermic process. The values of $\Delta \mathrm{S}^{*}$ in the presence and absence of the inhibitors are negative. This implies that the activation complex is the rate determining step representing association rather than dissociation, indicating that a decrease in disorder takes place on going from reactant to the activated complex [16].

\section{Galvanostatic polarization studies}

The effect of addition of some mono azo dyes compounds on the anodic and cathodic polarization curves of $\mathrm{Al}$ in $0.01 \mathrm{M} \mathrm{NaOH}$ was studied. The effect of increasing concentration of compound III is represented in Fig.6 as an example. However, similar curves were obtained for the other two compounds (not shown).

An inspection of the curves in Fig. 6 reveals that the presence of increasing concentration of the inhibitor causes a decrease in the corrosion rate, i.e., it shifted the anodic current-potential curves in the anodic direction and cathodic curves in the cathodic direction. This may be ascribed to adsorption of the inhibitor molecules on the metal surface. The corrosion current density $\left(\mathrm{I}_{\text {corr }}\right)$ was calculated by the extrapolation of anodic and cathodic Tafel lines with steady state (corrosion) potential. 


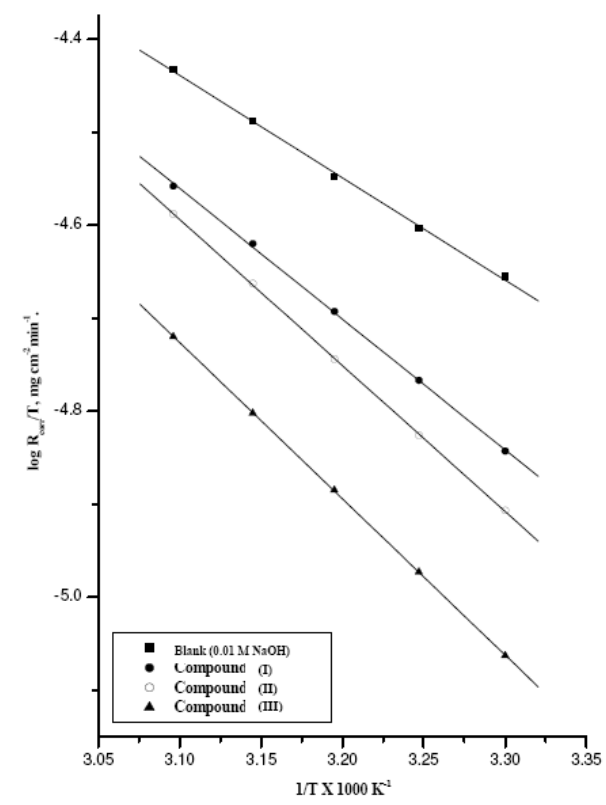

Figure 5. $\log \mathrm{R}_{\text {corr. }} / \mathrm{T}$ vs. $1 / \mathrm{T}$ for aluminium electrode in $0.01 \mathrm{M} \mathrm{NaOH}$ in the absence and presence of $5 \times 10^{-6} \mathrm{M}$ of the mono azo dyes compounds.

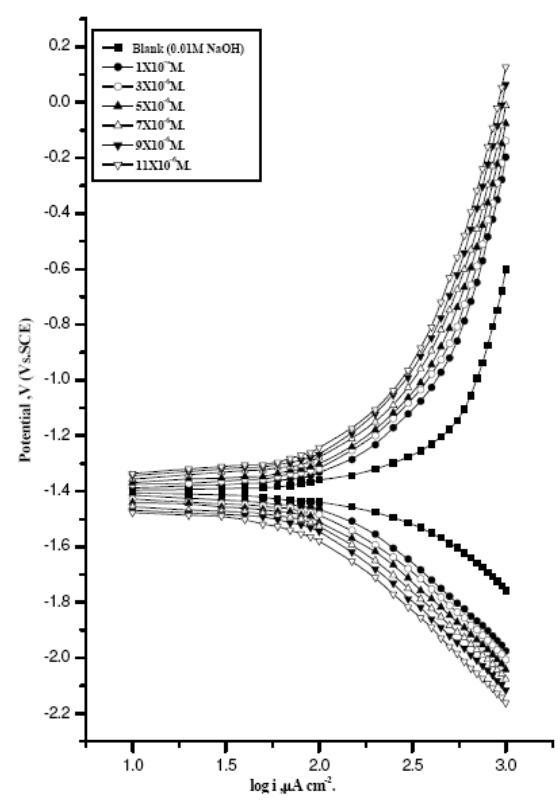

Figure 6. Galvanostatic polarization curves for the dissolution of aluminium in $0.01 \mathrm{M}$ $\mathrm{NaOH}$ in presence and absence of different concentrations of compound (III) at $30^{\circ} \mathrm{C}$.

Table 3 represents the effect of inhibitor concentrations on the corrosion parameters of $\mathrm{Al}$ electrode in $0.01 \mathrm{M} \mathrm{NaOH}$ solution. These parameters are anodic Tafel slope $\left(\beta_{\mathrm{a}}\right)$, cathodic Tafel slope $\left(\beta_{\mathrm{c}}\right)$, corrosion potential $\mathrm{E}_{\text {corr }}$, corrosion current density ( $\left.\mathrm{I}_{\text {corr }}\right)$ and inhibition efficiency (IE). 
Table 3. Corrosion parameters obtained from galvanostatic polarization technique of aluminium electrode in $0.01 \mathrm{M} \mathrm{NaOH}$ containing different concentrations of mono azo dyes compounds.

\begin{tabular}{|c|c|c|c|c|c|}
\hline Concentration, $\mathrm{M}$ & $-\mathrm{E}_{\text {corr. }}, \mathrm{mV}$ & $\mathrm{I}_{\text {corr. }}, \mu \mathrm{A} \mathrm{cm}^{-2}$ & $\beta_{\mathrm{a}}, \mathrm{mV} \mathrm{dec}{ }^{-1}$ & $\beta_{\mathrm{c}}, \mathrm{mV} \mathrm{dec}{ }^{-1}$ & $\% \mathrm{P}$ \\
\hline $0.00 \mathrm{M}$ compound I & 1203 & 938.41 & 4897 & 2326 & ------. \\
\hline $1 \times 10^{-6} \mathrm{M}$ compound I & 1211 & 634.93 & 4920 & 2350 & 32.34 \\
\hline $3 \times 10^{-6} \mathrm{M}$ compound I & 1212 & 606.21 & 5201 & 2597 & 35.40 \\
\hline $5 \times 10^{-6} \mathrm{M}$ compound I & 1214 & 584.72 & 5473 & 2853 & 37.69 \\
\hline $7 \times 10^{-6} \mathrm{M}$ compound I & 1216 & 553.85 & 5734 & 3121 & 40.98 \\
\hline $9 \times 10^{-6} \mathrm{M}$ compound I & 1217 & 530.48 & 6071 & 3471 & 43.47 \\
\hline $11 \times 10^{-6} \mathrm{M}$ compound I & 1220 & 510.21 & 6405 & 3770 & 45.63 \\
\hline 0.00 M compound II & 1203 & 938.41 & 4897 & 2326 & \\
\hline $1 \times 10^{-6} \mathrm{M}$ compound II & 1213 & 561.73 & 4936 & 2367 & 40.14 \\
\hline $3 \times 10^{-6} \mathrm{M}$ compound II & 1214 & 539.59 & 5216 & 2626 & 42.50 \\
\hline $5 \times 10^{-6} \mathrm{M}$ compound II & 1215 & 512.65 & 5497 & 2903 & 45.37 \\
\hline $7 \times 10^{-6} \mathrm{M}$ compound II & 1217 & 472.86 & 5766 & 3181 & 49.61 \\
\hline $9 \times 10^{-6} \mathrm{M}$ compound II & 1218 & 433.73 & 6109 & 3547 & 53.78 \\
\hline $11 \times 10^{-6} \mathrm{M}$ compound II & 1221 & 414.59 & 6456 & 3856 & 55.82 \\
\hline 0.00 M compound III & 1203 & 938.41 & 4897 & 2326 & ------- \\
\hline $1 \times 10^{-6} \mathrm{M}$ compound III & 1215 & 401.08 & 4944 & 2371 & 57.26 \\
\hline $3 \times 10^{-6} \mathrm{M}$ compound III & 1216 & 383.72 & 5222 & 2633 & 59.11 \\
\hline $5 \times 10^{-6} \mathrm{M}$ compound III & 1217 & 351.72 & 5512 & 2906 & 62.52 \\
\hline $7 \times 10^{-6} \mathrm{M}$ compound III & 1219 & 311.65 & 5785 & 3190 & 66.79 \\
\hline $9 \times 10^{-6} \mathrm{M}$ compound III & 1221 & 270.07 & 6146 & 3563 & 71.22 \\
\hline $11 \times 10^{-6} \mathrm{M}$ compound III & 1222 & 247.65 & 6497 & 3874 & 73.61 \\
\hline
\end{tabular}

Inspection of Table 3 shows:

i- $E_{\text {corr }}$ is shifted to more negative direction and $I_{\text {corr }}$ decreases. Hence the values of IE increase, indicating the inhibiting effect of these compounds.

ii- These compounds behave as mixed type inhibitors but the anode is more polarized when an external current density was applied $\left(\beta_{\mathrm{a}}>\beta_{\mathrm{c}}\right)$.

iii- The values of I.E. increase with increasing the concentration of the inhibitor and the order of IE decreases in the following order:

Compound III > Compound II $>$ Compound I

This sequence is in accordance with that obtained from weight loss measurements.

The inhibition efficiency of mono azo dyes compounds toward the corrosion of aluminum in $0.01 \mathrm{M} \mathrm{NaOH}$ can be explained on the basis of the number of adsorption sites, their charge density, molecular size, mode of interaction with the metal surface and ability to form metallic complexes [17].

The inhibitive effects of the studied compounds can be attributed to the formation of insoluble complexes by combination of the metal cation and mono azo dyes molecules on the metal surface according to the following reaction 


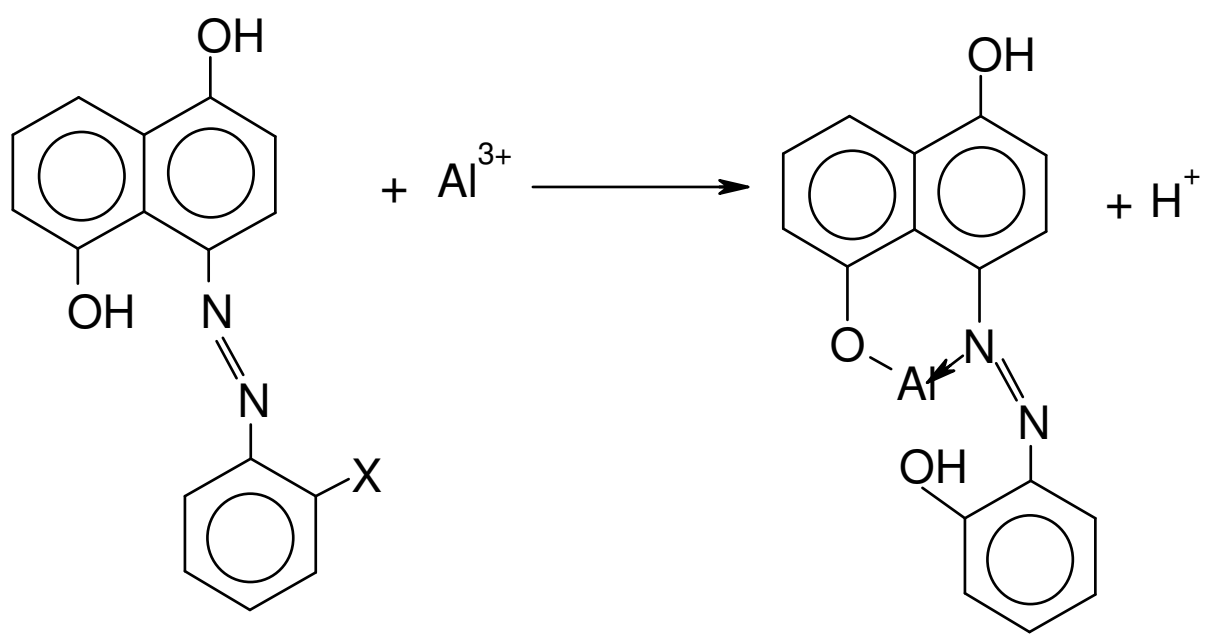

The results indicated that the IE's of mono azo dyes compounds (I-III) are more or less dependent on the nature of constituents. The inhibition efficiency decreases in the following order:

\section{Compound III $>$ Compound II $>$ Compound I}

The monoazodyes derivatives have either electron-donating groups such as $\mathrm{OCH}_{3}$ group in compound III, or electro with drowing group such as $-\mathrm{Cl}$ group in compound I. The above order of IE may be originated from the changing nature substituents in the ring. It is clear from the above sequence that compounds containing electron donating group are more efficient inhibitors than those containing electron withdrawing groups. The electrodonating groups enhance adsorption with a consequent increase in I.E.

\section{Conclusions}

1- The corrosion of $\mathrm{Al}$ in $0.01 \mathrm{M} \mathrm{NaOH}$ is inhibited by the addition of some mono azo dyes compounds.

2- The inhibition efficiency increases with increase in the concentration of these compounds, but decreases with an increase in temperature.

3- The inhibitive effect of these compounds is attributed to the formation of insoluble complex adsorbed on the metal surface.

4- The adsorption process follows Frumkin adsorption isotherm.

\section{References}

1. M. Abdallah, Corros. Sci. 46 (2004) 1981.

2. A.Y. El-Etre, H.E. Megahed, M. Abdallah and M.A. Obied, Corros. Prev. 32, March (2004).

3. S.S. Abd El-Rehim, H.H. Hassan and M.A. Amin, Mater. Chem. Phys. 78 (2002) 337.

4. M.L. Zheludkevich, K.A. Yasaku, S.K. Poznyak and M.G.S. Ferreira, Corros. Sci. 47 (2005) 3368.

5. M.M. Osman and S.S. Abd El-Rehim, Mater. Chem. Phys. 53 (1998) 34.

6. G.K. Gomma and M.H. Wahdan, Mater. Chem. Phys. 39 (1995) 209. 
7. M. Abdallah, Bull. Electrochem. 16(6) (2000) 258.

8. M.R. Saleh and A.M. Shams El-Din, Corros. Sci. 21 (6) (1981) 439.

9. $\quad$ P.B. Mathur and T. Vasudevan, Corrosion 38 (1982) 17.

10. G.A. El-Mahdy and S.S. Mahmoud, Corrosion 51(6) (1995) 436.

11. G. Moretti, G. Quartorone, A. Tassan and A. Zingales, Werkst. Korros. 45 (1994) 641.

12. B.B. Damaskin, O.A. Pedtri and V.V. Batra Kov, "Adsorption of Organic Compounds on Electrodes", Plenum Press, New York, p.86 (1971).

13. G. Trabanelli, in "Corrosion Mechanisms" (Ed. F. Mansfeld) Marcel Dekker, New York, 119 (1987).

14. K.M. Ralls, T.H. Courtney and J. Wullf, Introduction to Materials Science and Engineering, Wiley and Sons, New York, p.214 (1976).

15. S.T. Arab and E.M. Noor, Corrosion 49 (1993) 122.

16. S.S. Abd El-Rehim, M.A.M. Ibrahim and K.F. Khaled, J. Appl. Electrochem. 29 (1999) 593.

17. A.S. Fouda, M. Moussa, F. Taha and El-Neanaa, Corros. Sci. 26 (1986) 719. 